\title{
Memancing: Budaya Dan Nilai Kehidupan
}

\author{
Muhammad Habibi \\ Dosen Ilmu Administrasi Publik FISIP Universitas Widya Gama Mahakam Samarinda \\ e-mail: habibi.mayangmaurai@gmail.com
}

\begin{abstract}
Abstrak
Memancing merupakan salah satu aktifitas mata pencaharian yang sarat budaya dan nilai kehidupan dari zaman dahulu, namun pada kondisi kekinian memancing tidak hanya dilakukan oleh para nelayan tetapi juga oleh sebagian masyarakat yang ingin menikmati masa libur bahkan hingga menjadikan memancing sebagai sebuah hobi. Penelitian ini menggunakan pendekatan kualitatif deskriptif, dengan purposive sampling dan accidental sampling dengan tujuan untuk memahami dan menggali sisi budaya serta nilai-nilai kehidupan yang terkandung dalam kegiatan memancing.
\end{abstract}

Hasil penelitian menunjukkan, pertama, sisi budaya yang terkandung dalam kegiatan memancing (1) adalah bagian dari budaya turun temurun dari orang zaman dulu, yang mengajarkan cara menangkap dan mendapatkan ikan. Melalui kemampuan trias dinamika kebudayaan berupa cipta, rasa, dan karsa sebagai hasil dari pemikiran dan hati nurani menciptakan berbagai karya berupa peralatan mencari/menangkap ikan seperti jebakan ikan, jaring, bubu (perangkap ikan), sebatang bambu untuk alat pancing dari sebatang pohon bambu dari jenis khusus, kemudian dengan kemajuan ilmu pengetahuan, teknologi dan seni (IPTEKS) perkembangan jaman sekarang sebagian masyarakat mencari/menangkap ikan beralih menggunakan peralatan modern termasuk alat pancing (kreatifitas dan inovasi produk), dan (2) merupakan mata pencaharian, hobi, refreshing dari kejenuhan dan stress akibat aktifitas beban kerja yang tinggi. Kedua, nilai-nilai kehidupan yang terkandung didalam kegiatan memancing yakni tawakkal, kesabaran, keberuntungan (hoki), kedisiplinan, berbagi kebersamaan, pengalaman dan keilmuan, penguatan mentalitas, melahirkan semangat baru, mempertajam fokus, menghargai perbedaan baik pendapat, sikap, dan budaya, meningkatkan profesionalisme, selalu ada suasana baru ditiap tempat berbeda, membantu ketenangan (relaxing) dan kesegaran pikiran dan hati (refreshing), mengasah kemampuan (skill), serta menghargai, menjaga dan turut melestarikan kearifan lokal.

Kata kunci: memancing, budaya, nilai kehidupan, mata pencaharian, kearifan lokal, kreatifitas dan inovasi, dan trias dinamika kebudayaan.

\begin{abstract}
Fishing is one of the livelihood activities that are full of culture and values of life from ancient times, but in the current state of fishing is not only done by the fishermen but also by some people who want to enjoy the holiday even to make fishing as a hobby. This study uses descriptive qualitative approach, with purposive sampling and accidental sampling with the aim to understand and explore the cultural side and life values contained in fishing activities.

The results show, first, the cultural side contained in fishing activities (1) is part of the hereditary culture of the ancients, who taught how to catch and get fish. Through cultural dynamics in the form of inventiveness, taste, and intention as a result of thought and conscience creates various works in the form of fishing equipment such as fish trap, net, trap (fish trap), a bamboo for fishing from a bamboo tree and with the advancement of science, technology and art (IPTEKS) the development of the present day some people seek / catch fish to switch using modern equipment including fishing rods (creativity and product innovation), and (2) is a livelihood, hobby, refreshing of saturation and stress due to high
\end{abstract}


workload activity. Second, the values of life contained in the fishing activities of tawakkal, patience, luck (hockey), discipline, sharing togetherness, experience and scholarship, strengthening mentality, giving birth to new spirit, sharpening focus, appreciating differences of opinion, attitude and culture, improving professionalism, there is always a new atmosphere in different places, helping with relaxing and refreshing freshness, honing skills, and appreciating, maintaining and conserving local wisdom.

Keywords: fishing, culture, life value, livelihood, local wisdom, creativity and innovation, and cultural dynamics.

\section{Fenomena Memancing Kekinian}

Memancing pada dasarnya merupakan salah satu aktifitas mata pencaharian dari zaman dahulu hingga masa kini oleh sebagian masyarakat, terutama yang memang berprofesi sebagai nelayan. Meskipun demikian, kegiatan memancing memiliki kekhasan yang membuat individu merasa "terpancing" untuk mencoba kegiatan memancing.

Pada kondisi kekinian, memancing tidak hanya dilakoni oleh para nelayan tetapi juga oleh sebagian masyarakat yang ingin menikmati masa libur bahkan hingga menjadikan memancing sebagai sebuah hobi. Bentuk penguatan hobi terbukti dengan banyaknya club-club atau persatuan memancing. Terutama setelah booming program mancing mania di Trans 7, sehingga seolah memancing menjadi trend gaya hidup baru.

Meskipun demikian, ada juga sebagian orang ketika mendengar kata "memancing" langsung terbersit adalah kegiatan yang membosankan dan membuang waktu saja, bisa dibayangkan duduk atau berdiri berjam-jam hanya menunggu sesuatu yang tidak pasti otomatis biasanya kita akan mengalami titik jenuh. Kondisi ini dikarenakan memancing itu memang butuh kesabaran dan sedikit keberuntungan.

Berdasarkan pandangan tersebut, kita dapat pahami bahwa memancing termasuk kegiatan yang "mahal", karena mengandung sejumlah nilai, baik secara material maupun secara immaterial seperti tenaga dan lain sebagainya.

Menurut berbagai pandangan dan tulisan sering ditemui pernyataan bahwa yang namanya hobi sulit jika disinkronkan dengan logika. Terkadang pemilik hobi rela mengeluarkan anggaran yang diluar nalar, berlebihan, bahkan dikatakan sebagai pemborosan. Sekali lagi, baiknya jangan disinkronkan dengan logika.

Memancing pada sisi lain dapat dikatakan menjadi budaya oleh sebagian masyarakat, terutama yang berdomisili di daerah aliran sungai, rawa, maupun laut. Sehingga bagi masyarakat yang telah memiliki budaya memancing, sepadat apapun jadwal keseharian, maka akan berusaha untuk meluangkan waktu memancing meskipun sebentar, seperti menjelang petang atau di malam hari.

Pada ranah kebudayaan, tentunya tidak terlepas dari nilai-nilai yang diajarkan para leluhur dan terkandung dalam aktifitas memancing. Mulai dari pembuatan dan pemilihan bahan dasar untuk memancing hingga kegiatan memancing dilaksanakan.

\subsection{Permasalahan}

Adapun yang menjadi permasalahan dalam penelitian ini yakni apa dan bagaimana sisi budaya serta nilai-nilai kehidupan yang terkandung dalam kegiatan memancing

\subsection{Tujuan penelitian}

Adapun yang menjadi tujuan dalam penelitian ini berdasarkan bahasan penelitian dalam latar belakang di atas, sebagai upaya untuk memahami dan menggali sisi budaya serta nilai-nilai kehidupan yang terkandung dalam kegiatan memancing. 


\section{Memancing Dalam Bingkai Budaya Dan Kebudayaan}

a. Memancing

Menurut KKBI kata "memancing" diartikan sebagai menangkap ikan dengan pancing atau melakukan aktifitas mengail ikan. Sedangkan menurut Ahira (2016) "memancing dalam arti luas merupakan kegiatan menangkap ikan. Kegiatan menangkap ikan ini bisa merupakan pekerjaan, hobi, olah raga luar ruangan atau outdoor. Pada pelaksanaannya, memancing bisa dilakukan di pinggir atau di tengah danau, laut, sungai, dan perairan lainnya dengan target seekor ikan" (hlm. 1).

Dalam praktik dan dari hasil buruannya, tidak semua kegiatan memancing ikan ini selalu membuahkan hasil seekor ikan. Memancing tidak selalu identik dengan memancing ikan yang menjadi targetnya, memancing juga bisa mendapatkan penyu, cumi-cumi, gurita, udang dan lainnya.

Pada dasarnya, memancing ikan dapat dibedakan berdasarkan alam buruan, yaitu:

1. Memancing ikan air tawar

2. Memancing ikan air laut.

Sedangkan dalam praktiknya, memancing dapat dibedakan berdasarkan tempat atau lokasi memancing, yakni: embung air, kolam pemancingan, tambak ikan, sungai, rawa-rawa, danau, muara sungai, dan laut.

\section{b. Budaya}

Mengacu pada konteks bahasa Indonesia, "kebudayaan berasal dari bahasa Sansakerta "buddhaya", yaitu bentuk jamak dari buddhi yang berarti budi atau akal" (Prasetya, dkk, 2011, 28). Sedangkan menurut Rafiek (2012) "budaya diartikan sebagai "hasil budi daya cipta manusia" sehingga dapat diartikan sebagai "keseluruhan gagasan, karya dan akal budi manusia yang diciptakannya dengan sengaja dan terus dikembangkan demi kepentingan, kebutuhan, kesejahteraan, kedamaian, kemakmuran, dan kepuasan hidupnya" (hlm.7).

E.B. Taylor dalam Setiadi dkk (2006) menyatakan bahwa "budaya adalah suatu keseluruhan kompleks yang meliputi pengetahuan, kepercayaan, kesenian, moral, keilmuan, norma, adat istiadat, dan kemampuan yang lain serta kebiasaan yang didapat oleh manusia sebagai anggota masyarakat" (hlm.27)

Menurut Koentjaraningrat (2011:74) bahwa ada 4 (empat) wujud kebudayaan, yaitu:

a. Kebudayaan sebagai artifacs, atau benda-benda fisik.

b. Kebudayaan sebagai sistem tingkah laku dan tindakan berpola (sistem Sosial).

c. Kebudayaan sebagai sistem gagasan (sistem budaya).

d. Kebudayaan sebagai sistem gagasan yang ideologis (nilai budaya).

Dengan demikian secara keseluruhan budaya dan kebudayaan adalah menyangkut keseluruhan aspek kehidupan manusia baik fisik maupun non fisik sebagai hasil dari akal budi manusia yang bersifat komplek dan dilakukan secara terus menerus.

\section{c. Nilai}

Menurut Sobur (2009: 374) nilai merupakan "konstruk dasar untuk teori dan riset dalam disiplin ilmu sosiologi dan antropologi". Menurut kamus besar bahasa Indonesia "nilai adalah sifat-sifat (halhal) yang penting atau berguna bagi kemanusiaan" (hlm.1005).

Dalam ranah antropologi sosial, nilai dalam pandangan Clyde Kluchohn (1985) dalam Mueller (1986) bahwa nilai adalah "suatu konsepsi, eksplisit, implisit, yang khas untuk seorang individu atau suatu kelompok, dari yang diinginkan yang mempengaruhi seleksi modus, cara, dan tujuan tindakan yang tersedia" (Sobur, 2009:374). Sedangkan menurut Spranger, nilai adalah suatu tatanan yang 
dijadikan panduan oleh individu untuk menimbang dan memilih alternatif keputusan dalam situasi sosial tertentu" (Ali dan Asrori, 2010, hlm.5).

Nilai-nilai berhubungan erat dengan kehidupan sebagai hasil kebudayaan, atau salah satu unsur kebudayaan adalah nilai-nilai hidup dan kehidupan. Jika kebudayaan dimengerti sebagai hasil cipta manusia untuk memperbaiki, mempermudah, dan meningkatkan kualitas diri; maka nilai-nilai hidup dan kehidupan merupakan hasil kebudayaan. Akan tetapi, jika kebudayaan dimengerti sebagai keseluruhan kemampuan [pikiran, kata, dan tindakan atau perbuatan] manusia; maka nilai-nilai hidup dan kehidupan merupakan unsur-unsur kebudayaan yang digunakan untuk berinteraksi dengan lingkungan dan sesuai situasi dan kondisi tertentu (Jappy, 2013, hlm.1).

Dengan demikian, antara budaya, kebudayaan dan nilai-nilai dalam kehidupan saling terkait dan menjadi saling penguat diantara ketiganya. Begitupun dengan aktifitas memancing, memiliki unsur budaya dan nilai-nilai kehidupan yang terkandung didalamnya.

\section{Metode Penelitian}

Berdasarkan permasalahan dan tujuan penelitian, maka jenis penelitian ini adalah penelitian kualitatif dengan pendekatan deskriptif atau bersifat "menggambarkan" makna yang terkandung dalam kegiatan memancing baik dari sisi budaya maupun sisi nilai kehidupan.

Teknik pengumpulan data pada penelitian ini dilakukan melalui studi kepustakaan, wawancara mendalam, dan observasi, dengan informan 23 (dua puluh tiga) orang secara purposive sampling dan accidental sampling.

Analisis menggunakan model analisis interaktif teori Miles dan Huberman (1994), yakni reduksi data, tampilan data, kesimpulan: gambaran dan verifikasi.

\section{Hasil Penelitian}

Mengacu pada teori yang dikemukakan oleh Ahira (2016) tentang memancing sebagaimana dijelaskan pada Tinjauan Pustaka huruf a, serta teori tentang budaya yang dikemukakan oleh E.B. Taylor dan Koentjaraningrat pada huruf b, maka pada bagian ini akan peneliti sajikan pembahasan dan analisa penelitian berdasarkan teori tersebut dikorelasikan dengan informasi dari para informan.

1) Sisi budaya dalam kegiatan memancing.

Pada sisi budaya ini terdapat 2 (dua) poin utama yang peneliti klasifikasikan berdasarkan pernyataan para informan, yakni: memancing merupakan bagian dari budaya, dan sebagai gaya hidup baru dalam modernitas sosial kekinian, dengan pembahasan analisis sebagaimana dibawah ini.

a) Memancing merupakan bagian dari budaya

Secara umum ada 4 (empat) kategori pernyataan para informan berdasarkan pada wawasan tentang budaya dan kebudayaan. Pertama, informan menyadari bahwa memancing adalah kegiatan budaya karena merupakan warisan turun temurun dari nenek moyang. Kedua, bahwa memancing bagian dari kearifan lokal. Ketiga, bukanlah budaya melainkan hanya hobi untuk kesenangan. Keempat, memancing juga dilakukan orang hampir diseluruh dunia.

Jika dispesifikasikan keempat kategori tersebut, maka sesungguhnya terdapat 2 (dua) pernyataan yang berbeda, yakni ada yang menyatakan memancing adalah kegiatan budaya, dan pada pendapat lain menyatakan bahwa kegiatan memancing bukanlah budaya. sekali lagi bahwa perbedaan pernyataan ini karena perbedaan pengetahuan budaya dan kebudayaan dari para informan.

Jika diperhatikan dengan seksama, maka kedua kontradiksi pernyataan tersebut bertitik pada kategori kedua yakni bahwa memancing bagian dari kearifan lokal. Sehingga ada kecenderungan sebagian informan memahami bahwa suatu kebudayaan haruslah bersifat 
kearifan lokal, dan ketika aktifitas memancing dilakukan oleh sebagian masyarakat dunia atau menjadi suatu kegiatan global maka dipandang bukan suatu budaya atau menjadi kebudayaan.

Namun jika mengacu pada teori yang dikemukakan oleh E.B. Taylor, maka kegiatan memancing merupakan suatu kebudayaan, karena didalam kegiatan memancing terdapat pengetahuan, kepercayaan, kesenian, moral, keilmuan, norma, adat istiadat, dan kemampuan yang lain serta kebiasaan yang dilakukan oleh manusia sebagai bagian dari anggota masyarakat.

Selain itu, jika ditinjau dari kategori kedua yakni kearifan lokal, maka ada kemungkinan perbedaan spesifik jenis sumber daya yang digunakan dalam memancing. Jika sebagian besar wilayah Kalimantan Timur para pemancing menggunakan bambu di jaman dahulu dan sebagian di jaman sekarang, ada kemungkinan penggunakan sumber daya material selain bambu di wilayah lain di Indonesia bahkan dunia yang mencirikan kearifan lokal. Seperti di wilayah Timor yang banyak pohon sagu, ada kemungkinan para nelayan atau pemancing menggunakan pelepah pohon sagu atau bagian dari batang pohon lain yang digunakan sebagai alat memancing yakni kail.

Kecenderungan adanya kecirian kearifan lokal dalam kegiatan memancing juga dapat terjadi pada keyakinan-keyaninan yang dianut dan dipandang mengandung unsur kepercayaan pada sisi sistem ilmu ghaib dan sistem religi, yang dikorelasikan dengan pernyataan sebagian informan bahwa ada cara memilih batang bambu yang dipergunakan sebagai kail seperti kepercayaan ruas bertemu ruas yang dipercaya memiliki hoki dalam memancing. Selain itu, adanya do'a-do'a dalam bentuk azimat yang diselipkan pada ruas batang bambu yang digunakan, atau pemilihan batang bambu pada hari-hari tertentu.

Bahkan kepercayaan tersebut, juga dimiliki para nelayan yang nota bene adalah pencari ikan yang kebanyakan adalah mewarisai budaya turun temurun dari nenek moyang mereka, dimana ada sebagian nelayan di Indonesia ketika akan bernelayan ke laut harus memperhitungkan kondisi cuaca, arah angin, perbintangan, perhitungan bulan dan waktu keberangkatan. Kepercayaan tersebut merupakan bagian dari kearifan lokal yang diyakini dapat memberikan keberuntungan dan berpengaruh terhadap hasil tangkapan.

b) Memancing sebagai gaya hidup baru dalam modernitas sosial kekinian

Pada konteks kekinian, kegiatan memancing bukan lagi milik sebagian masyarakat terutama bagi individu yang bermata pencaharian menangkap ikan, baik di laut, sungai, danau, rawa, dan tempat lain. Namun, kegiatan memancing telah berkembang kearah hobi atau rekreasi untuk sekedar melepas kejenuhan karena aktifitas kerja diperkantoran yang membutuhkan penyegaran baik suasana, menenangkan pikiran (refreshing), hingga hanya untuk meningkatkan kebersamaan.

Tayangan program Mancing Mania di salah satu televisi swasta nasional diyakini sebagai pelopor inspirasi bagi banyaknya program memancing di stasiun televisi lain di Indonesia, meskipun program mancing mania juga merupakan adopsi dari tayangan program memancing dari televisi luar negeri, namun tayangan di Indonesia yang memiliki dampak begitu besar bagi "penggila" memancing adalah program Mancing Mania.

Kegiatan memancing sebagai suatu hobi baru yang menjadi tren sebagai gaya hidup (lifestyle) bagi sebagian masyarakat bukanlah sebuah kegiatan yang murah. Peralatan yang digunakan cenderung modern dengan material yang sangat aplikatif, mudah dan modern, serta sebagian besar masih impor dari negara lain.

Modernitas peralatan tersebut melahirkan gengsi tersendiri bagi pengguna, baik individu maupun kelompok memancing yang dikenal dengan Club Memancing.

Memancing sebagai gaya hidup bagi sebagian besar "mancing mania" dinyatakan dengan sejumlah pernyataan informan yang telah dikemukakan pada bagian IV Hasil dan Pembahasan huruf a poin 1) huruf (b) diatas. 
Dengan demikian, kegiatan memancing dapat dikatakan sebagai bagian dari budaya dan kebudayaan masyarakat dari dulu hingga saat ini sebagaimana teori yang dikemukan oleh E.B. Taylor dan Kontjaraningrat dengan pencirian kebudayaan melalui 4 (empat) wujud kebudayaan, dimana kegiatan atau aktifitas memancing menyangkut keseluruhan aspek kehidupan manusia baik fisik maupun non fisik sebagai hasil akal budi manusia yang dilakukan terus menerus yang disertai dengan sejumlah keyakinan dan kepercayaan serta berdasarkan kemajuan ilmu pengetahuan, teknologi, dan seni dalam bingkai inovasi.

\section{2) Nilai-nilai kehidupan dalam kegiatan memancing.}

Sebagaimana permasalahan yang diangkat dalam penelitian ini, bahwa di dalam kegiatan memancing terkandung nilai-nilai kehidupan yang luhur. Berdasarkan informasi yang berhasil dihimpun dari para informan dapat dipahami bahwa terdapat sejumlah nilai yakni tawakkal, kesabaran, keberuntungan (hoki), kedisiplinan, berbagi kebersamaan, pengalaman dan keilmuan, penguatan mentalitas, melahirkan semangat baru, mempertajam fokus, menghargai perbedaan baik pendapat, sikap, dan budaya, meningkatkan profesionalisme, selalu ada suasana baru ditiap tempat berbeda, membantu ketenangan (relaxing) pikiran dan hati (refreshing), serta menghargai, menjaga dan turut melestarikan kearifan lokal.

Sebagai bangsa yang ber-Pancasila, adalah wajar jika terdapat informan yang menyatakan bahwa nilai yang terkandung dalam kegiatan memancing adalah tawakkal atau berserah diri kepada Tuhan YME atas segala usaha yang dilakukan termasuk dalam memancing, mengingat dalam kegiatan memancing ada mengandung unsur keberuntungan, sehingga segala rezeki dari memancing diserahkan kepada Tuhan YME.

Pada kegiatan memancing juga terkandung nilai profesionalitas artinya jika ingin memperoleh hasil sebagaimana yang diharapkan harus dilengkapi dengan sikap profesional, seperti pandai memilih jenis umpan, memilih kail, rutin merawat peralatan memancing, pintar membaca cuaca dan kondisi air, pikiran fokus dalam memancing, sepenuh hati, sabar, mentalitas yang kuat dan sikap profesional lain.

Penguatan aplikasi ilmu pengetahuan dan teknologi dalam konteks kekinian juga mutlak diperlukan mengingat dinamika lingkungan dan budaya yang terjadi disekitar kita. Para pemancing saat ini dan ketersediaan material peralatan memancing dengan mudahnya dapat memperoleh ikan yang begitu besar dengan ukuran joran (kail) yang kecil, perhatikan juga bagaimama benang yang digunakan tidak mudah putus bahkan oleh gigi ikan yang tajam sekaliber gigi hiu. Begitulah nilai-nilai kehidupan berpadu dengan ilmu pengetahuan, teknologi dan seni (IPTEKS).

Berdasarkan pandangan Clyde Kluchohn (1985) sebagaimana yang telah diuraikan pada Bagian II Tinjauan Pustaka huruf c bahwa kegiatan memancing dapat dikatakan sebagai kegiatan yang khas untuk seorang individu atau suatu kelompok yang memiliki nilai dan berhubungan dengan budaya sebagai wujud interaksi dengan lingkungan dan penggunaan akal pikiran sebagai dasar perwujudan trias dinamika kebudayaan.

Kenyataan tersebut menjadi kontruk dasar teori dan riset terutama adalam riset disiplin ilmu sosiologi, budaya, dan antropologi sebagai hasil dari aktifitas manusia sebagaimana yang diungkapkan Sobur (2009).

\section{Kesimpulan}

1) Sisi budaya yang terkandung dalam kegiatan memancing (1) adalah bagian dari budaya turun temurun dari orang zaman dulu, yang mengajarkan cara menangkap dan mendapatkan ikan. Melalui kemampuan trias dinamika kebudayaan berupa cipta, rasa, dan karsa sebagai hasil dari pemikiran dan hati nurani menciptakan berbagai karya berupa peralatan mencari/menangkap ikan seperti jebakan ikan, jaring, bubu (perangkap ikan), sebatang bambu untuk alat pancing dari sebatang pohon bambu dari jenis khusus, kemudian dengan kemajuan ilmu pengetahuan, teknologi dan seni (IPTEKS) perkembangan jaman sekarang sebagian masyarakat 
mencari/menangkap ikan beralih menggunakan peralatan modern termasuk alat pancing (kreatifitas dan inovasi produk), dan (2) merupakan mata pencaharian, hobi, refreshing dari kejenuhan dan stress akibat aktifitas beban kerja yang tinggi.

2) Nilai-nilai kehidupan yang terkandung didalam kegiatan memancing yakni tawakkal, kesabaran, keberuntungan (hoki), kedisiplinan, berbagi kebersamaan, pengalaman dan keilmuan, penguatan mentalitas, melahirkan semangat baru, mempertajam fokus, menghargai perbedaan baik pendapat, sikap, dan budaya, meningkatkan profesionalisme, selalu ada suasana baru ditiap tempat berbeda, membantu ketenangan (relaxing) dan kesegaran pikiran dan hati (refreshing), mengasah kemampuan (skill), serta menghargai, menjaga dan turut melestarikan kearifan lokal.

\section{DAFTAR PUSTAKA}

Buku:

Ali, Mohammad, dan Mohammad Asrori. 2010. Psikologi Remaja: perkembangan peserta didik. Jakarta: PT. Bumi Aksara.

Alston, Margaret., \& Wendy Bowles. 2003. Research for social workers: and introduction to methods $\left(2^{\text {nd }}\right.$ ed.). Canberra: Allen \& Unwin.

Denzim, Norman K., Yvonna S. Lincoln. 2009. Handbook of qualitative research (Dariatno dkk, Penerjemah). Yogyakarta: Pustaka Pelajar.

Field, John. (2003). Social capital. (Nurhadi, penerjemah). Bantul: Kreasi Wacana Offset.

Irawan, Prasetya. 2006. Penelitian kualitaif \& kuantitatif untuk ilmu-ilmu sosial. Depok: Departemen Ilmu Administrasi FISIP UI.

Koentjaraningrat. 2011. Pengantar Antropologi I. Jakarta: PT. Rineka Cipta.

Kuper, Adam \& Jessica Kuper. 2000. Ensiklopedi ilmu-ilmu sosial. Haris Munandar, et.al. (Penerjemah). Jakarta: PT. Raja Grafinso Persada.

Lawang, Robert M.Z. (2004). Kapital Sosial: dalam perspektif sosiologik, suatu pengantar. Jakarta: FISIP UI Press.

Miles, Matthew B., \& A. Michael Huberman. 1994. Qualitative data analyses (second edition). London: SAGE Publications.

Moleong, Lexy J. 2010. Metodologi penelitian kualitatif (Ed. Revisi). Bandung: PT. Remaja Rosdakarya.

Muhammad, Abdulkadir. 2011. Ilmu Sosial dan Budaya Dasar. Bandung: PT. Citra Aditya Bakti.

Ndraha, Taliziduhu. 2010. Metodologi ilmu pemerintahan. Jakarta: Rineka Cipta.

Neuman, W. Lawrence. 2006. Social Research Methods: Qualitatative and Quantitative Approaches. (4 th ed). USA: Allyn and Bacon.

Ogden, Russel. (2008). “Informant”. Ed. Given, Lisa M. The sage encyclopedia of qualitative research methods volumes $1 \& 2$. UK: London, SAGE Publications, Inc. 430-431.

Pahmi Sy. 2010. Perspektif baru antropologi pedesaan. Jakarta: gaung Persada Press.

Prasetya, Joko Tri. 2011. Ilmu Budaya Dasar. Jakarta: Rineka Cipta.

Qodratillah, Meity Taqdir, dkk. 2008. Kamus Bahasa Indonesia. Pusat Bahasa Departemen Pendidikan Nasional Jakarta. 
Raco, J.R. (2010). Metode penelitian kualitatif: jenis, karakteristik dan keunggulannya. Jakarta: PT. Gramedia Widiasarana Indonesia.

Rafiek, M. 2012. Ilmu Sosial dan Budaya Dasar. Yagyakarta: Aswaja Pressindo.

Rahardjo. 2010. Pengantar sosiologi pedesaan dan pertanian. Yogyakarta: Gadjah Mada University Press.

Schensul, Jean J. (2008). "Methodology". Ed. Given, Lisa M. The sage encyclopedia of qualitative research methods volumes 1 \& 2. UK: London, SAGE Publications, Inc. 516-521.

Setiadi, Elly M., Kama A. Hakam, \& Ridwan Effendi. 2006. Ilmu Sosial dan Budaya Dasar (Ed.2). Jakarta: Kencana.

Sobur, Alex. (2009) Psikologi umum:dalam lintasan sejarah. Bandung: CV. Pustaka Setia.

Strauss, Anselm L. (1987). Qualitative analysis for social scientists. UK: Cambridge University Press.

Sugiyono.(2005). Memahami Penelitian Kualitatif, Bandung: Alfabetha

Sugiyono. (2010). Metode penelitian kuantitatif, kualitatif dan $R \& D$. Bandung: Alfabeta

Topatimasang, Roem., Mansur Faqih, dan Toto Rahardjo.(2000). Mengubah Kebijakan Publik, Yogyakarta: Pustaka Pelajar

Piliang, Yasraf Amir, 2010, Post-Realitas: Realitas Kebudayaan Dalam Era Post-Metafisika, Jalasutra, Yogyakarta.

Vanderstoep, Scott W., \& Dierdre D. Johnston. (2009). Research methods for everyday life: blending qualitative and quantitative approaches. CA: San Fransisco. John Wiley \& Sons, Inc.

Walliman, Nicholas. (2006). Social Research Methods. UK: London SAGE Publications

$\underline{\text { Jurnal: }}$

Krefting, Laura. (1991). Rigor in qualitative research: the assessment of trustworthiness. The American Journal of Occupational Therapy, 214-222. Vol. 45, No. 3.

Peraturan Perundang-undangan:

Undang-Undang Republik Indonesia Nomor 6 Tahun 2014 Tentang Desa

Website:

Ahira, Anne. (2016). Memancing. http://www.anneahira.com/memancing.htm

Goncing, Muhammad Abdi. 2016. Bahasa, Pikiran, dan Realitas. Diunduh pada 19 Mei 2016. http://www.academia.edu/2025853/bahasa_pikiran_dan_realitas

Hidayatullah, Wahyu. 2015. Pengertian dan konsep realitas sosial budaya. Diunduh pada 19 Mei 2016. http://www.trendilmu.com/ 2015/06/pengertian-dan-konsep-realitas-sosial.html\#

Jappy, Oppa. 2013. Nilai-nilai hidup dan kehidupan. Download 8 Mei 2017. http://www.kompasiana.com/opajappy/nilai-nilai-hidup-dankehidupan_55287adaf17e61d4548b4567

Rohman, Fatkhur. 2011. Perilaku manusia \& nilai sosial. Di download 19 Mei 2016. http://ruhtaf12.blogspot.co.id/2011/12/perilaku-sosial-dan-perubahan-sosial.html 